\title{
Hegemonia e ensino de História: algumas considerações sobre o Mato Grosso do Sul
}

Hegemony and History Teaching: Some Considerations about Mato Grosso do Sul

Renato Jales Silva Júnior

RESUMo

$\mathrm{O}$ artigo objetiva discutir alguns aspectos da história de Mato Grosso do Sul e sua relação com o ensino de História. Mais especificamente abordaremos a produção de sentidos hegemônicos sobre o território a partir da divisão política do antigo Mato Grosso e a disputa por memórias que se inicia nesse processo. A produção historiográfica sobre a criação do estado de Mato Grosso do Sul é marcada majoritariamente pela discussão do conceito de identidade. $\mathrm{Na}$ proposta deste texto deslocamos a discussão para o conceito de hegemonia para pensarmos as ações dos grupos política e economicamente dominantes como tentativas de se criar memórias hegemônicas para conseguir um consenso sobre quais seriam os modos de viver legítimos no estado.

Palavras-chave: memória; Mato Grosso do Sul; ensino de história.

\section{Abstract}

This work aims to discuss some aspects of the history of Mato Grosso do Sul and its relation with the teaching of History. More specifically we will approach the production of hegemonic meanings over the territory from the political division of the former Mato Grosso and the dispute for memories that begins in this process. The historiographic production on the creation of the state of Mato Grosso do Sul is marked mainly by the discussion of the concept of identity. In the proposal of this text we move the discussion to the concept of hegemony to think the actions of the politically and economically dominant groups as attempts to create hegemonic memories to reach a consensus on what would be the legitimate ways of living in the state. Keywords: memory; Mato Grosso do Sul; history teaching.

\footnotetext{
* Universidade Federal de Mato Grosso do Sul (UFMS), Coxim, MS, Brasil. rehistoriador@yahoo. com.br
} 
Este artigo sintetiza alguns esforços por mim empreendidos para amalgamar supostos teóricos e metodológicos da História Social com as discussões sobre o ensino de História. Meus trabalhos de Mestrado (Silva Júnior, 2006) e Doutorado (Silva Júnior, 2013) tiveram como problemática central a constituição dos lugares na cidade de Uberlândia e as muitas memórias produzidas sobre esses processos. Interessou-me entender como sujeitos comuns recuperavam em suas narrativas orais os momentos marcantes de suas vidas e como interpretavam as mudanças vividas nessa cidade. A intenção foi colocar em disputa essas memórias privadas com aquelas que se tornaram públicas e que privilegiavam os detentores do poder político e econômico na cidade silenciando a grande maioria.

Para trazer esses sujeitos à cena história como protagonistas e questionar as memórias oficializadas por diferentes instituições tais como a imprensa e o poder público, busquei inspiração em autores alinhados à tradição marxista tais como os historiadores Edward Palmer Thompson e Christopher Hill e o crítico literário Raymond Williams. Eles foram importantes para entender o conceito de memória e como as memórias são produzidas e reproduzidas na sociedade.

Thompson (1987) e Hill (1987) trouxeram enormes contribuições ao propor uma história protagonizada por sujeitos comuns que atuavam, faziam escolhas, propunham novos projetos de sociedade e os disputavam com aqueles que detinham o poder hegemônico na sociedade. Raymond Williams (2005) se apropriou do conceito de hegemonia de Antonio Gramsci para entender como se dava o exercício da dominação em diferentes momentos históricos e, mais do que isso, para mostrar que os sujeitos sociais conseguem em determinados momentos provocar fissuras nas concepções dominantes. Williams assim explica esse processo:

Uma das grandes contribuições de Gramsci é que ele enfatiza a questão da hegemonia, e a compreende numa profundidade que considero rara. Pois hegemonia supõe a existência de algo verdadeiramente total, que não é meramente secundário ou superestrutural, como na acepção fraca de ideologia, mas que é vivido numa tal profundidade e satura a sociedade de tal maneira que, como Gramsci coloca, constitui a substância e o limite do senso comum para muitas pessoas sob sua influência e corresponde à realidade da experiência social muito mais 
claramente do que quaisquer noções derivadas da fórmula de base e superestrutura. (Williams, 2005, p. 215)

O exercício da dominação segundo esse suposto enriquece a análise dos processos históricos ao incorporar a produção e "divulgação" de valores e como estes auxiliam os grupos dominantes a tornar suas concepções aceitas como únicas. Esse é um movimento dialético na medida em que os valores hegemônicos são constantemente pressionados por outros, produzidos por grupos subalternos.

Ao criticar a noção de ideologia como um conjunto de ideias localizadas na superestrutura e que foram impostas de maneira direta pela base, Gramsci e Williams mostram que os produtos culturais são fundamentais para a emergência e afirmação de grupos dirigentes e que eles nunca são puros, isto é, estão contaminados por valores dos grupos subalternos. Nos seus estudos sobre a formação da classe operária inglesa, Thompson faz um caminho parecido ao dedicar suas análises às questões culturais e ao processo de apropriação dos novos valores burgueses aos trabalhadores, bem como à maneira como estes últimos reconstroem e devolvem os valores propondo novas pautas e exercendo constantes pressões.

Aproprio-me desses supostos teóricos para refletir sobre a produção de sentidos no ensino de História, mais especificamente as relações de poder expressas historicamente na construção dos currículos. Entendo que essas relações de poder disputadas especificamente na construção de diretrizes curriculares na área de história estão relacionadas com os processos de produção de memórias, e estas se inscrevem na emergência de determinados sujeitos e no silenciamento de outros.

Para pôr em movimento esse suposto escolhi refletir sobre o processo de divisão do estado de Mato Grosso do Sul e as memórias produzidas historicamente. Ainda sobre esse tema interpretarei ao longo deste artigo os desdobramentos desse fato político na historiografia e no ensino de História, e como tal processo é incorporado ao currículo de História no estado como saber a ser ensinado.

Além de incorporar o conceito de hegemonia em suas análises, Williams constrói um movimento muito rico para pensar a dialética de constituição da 
dominação, as pressões que esta sofre para se manter e as práticas de incorporação de outros valores:

O próximo passo é introduzir uma distinção entre formas residuais e emergentes, tanto da cultura alternativa como da de oposição. Por "residual" quero dizer que algumas experiências, significados e valores, que não podem ser verificados ou expressos nos termos da cultura dominante, são, apesar de tudo, vividos e praticados sobre a base de um resíduo - tanto cultural quanto social - de alguma formação social prévia [...]. Por "emergente" entendo, primeiro, que novos significados e valores, novas práticas, novas significações e experiências, são criadas continuamente. Mas a tentativa de incorporá-las é imediata, só porque são parte - e ainda assim nem mesmo uma parte definida - da prática contemporânea efetiva. De fato, é significativo como essa tentativa é rápida em nosso tempo, e como a cultura dominante está alerta, agora, a qualquer coisa que possa ser tida como emergente. (Williams, 2005, p. 218-219)

Apreendemos esse procedimento que além de teórico e metodológico é também um olhar político sobre a produção, circulação e incorporação de valores culturais para entendermos o conceito de memória. Assim, analisaremos o processo de divisão do estado de Mato Grosso do Sul não somente no seu ato político, pois, como alerta a pesquisadora Yara Aun Khoury, "processos sociais criam significações, e [...] essas se instituem em memórias" (Khoury, 2006).

A divisão do antigo estado de Mato Grosso em 1977, com perda de sua parte sul, é um fato político importante na medida em que cria um novo estado e, com este, a necessidade de produzir símbolos de identificação com o território. Essa produção se faz por diferentes meios e tem como recurso privilegiado a eleição de determinados sujeitos como protagonistas e a seleção do que será lembrado para afirmar as memórias hegemônicas e manter os grupos dominantes como a estrutura de poder que foi criada. Posteriormente, esses produtos culturais são disseminados por diferentes instituições, entre elas a escola.

Meu primeiro contato com a temática divisionista se deu na leitura das diretrizes curriculares do estado para ajudar os alunos da disciplina de Estágio Obrigatório a construir seus planos de aula. Encontramos referência à temática no $3^{\circ}$ ano do Ensino Médio e no $9^{\circ}$ do Ensino Fundamental (Secretaria..., 
2012). Procuramos saber com os professores de História como esse tema era trabalhado e ouvimos que, por utilizarem os livros didáticos para preparação dos planos de aula, raramente tratavam do tema. Quando o faziam, utilizavam material disponibilizado pela Secretaria de Educação.

Em documento disponibilizado pela Secretaria intitulado "Sugestões $3^{\circ}$ bimestre - ensino fundamental" (Secretaria..., 2016), no ano de 2016 encontramos um link que direciona os professores e pesquisadores do tema para o sítio digital www.Ilovemsoficial.com, que em 2014 publicou um texto resumindo o processo de divisão. Seus autores iniciam justificando o nome:

Nessa matéria queremos deixar claro o porquê da nossa insistência de sermos reconhecidos como Sul-Mato-Grossenses do estado de Mato Grosso do Sul e o motivo que nos leva a lutar pelo nome desse estado que foi conquistado com muita luta e que não iniciou em 11 de outubro de 1977. Isso veio perseguido por nossos conterrâneos desde o final do século XIX. (Movimento..., 2011)

Esse trecho, que versa sobre a divisão, destaca parcialmente quais seriam os sujeitos desse processo e ganha importância neste artigo por ser utilizado como referência para orientar os professores sobre o processo, transformando-se em conhecimento a ser ensinado.

Em seguida, o texto apresenta o que considera uma característica específica da região que fundamentaria a separação:

A resistência sul-mato-grossense é uma das peculiaridades que entremeiam a história de Mato Grosso do Sul. O movimento divisionista tem sua origem nos fins do século XIX, 1889, quando alguns políticos corumbaenses divulgam um manifesto. A sistematização da pecuária, o desenvolvimento socioeconômico das vilas e cidades, a exploração da erva-mate pela Companhia Matte Laranjeira e a ligação entro o Sul de Mato Grosso e São Paulo marcaram a origem do movimento divisionista que foi dividido em quatro grandes fases [...]. (Movimento..., 2011)

Essa história reafirma o que chamamos aqui de memória dominante. Definiremos esse conceito com o apoio do Grupo de Memória Popular (2004). Para esse Grupo existem algumas maneiras de produzir sentidos do passado: "por meio de representações públicas e por meio da memória privada (que, no entanto, também pode ser coletiva e compartilhada)" (Grupo Memória 
Popular, 2004, p. 283). Interessa-nos neste momento entender melhor a produção das primeiras representações:

A primeira representação envolve um 'teatro' público da história, um palco público e uma audiência pública [...]. Este palco público é ocupado por muitos atores que, muitas vezes, falam a partir de scripts contraditórios, mas denominaremos o conjunto dos elementos que constituem essa esfera pública e controlam o acesso aos meios de produção de o "aparato histórico". Chamaremos os produtos desses mecanismos, no conjunto de suas relações e combinações em qualquer momento, de "o campo das representações públicas da história". Pensando sobre as maneiras como estas representações afetam concepções individuais ou de grupos do passado, podemos falar em "memória dominante". (Grupo Memória Popular, 2004, p. 284)

A escolha dos sujeitos que estariam envolvidos no processo de divisão do estado - políticos corumbaenses - como exposto no documento citado é parte significativa da construção de uma "representação pública" que tem como objetivo legitimar a existência do novo estado e afirmar o poder político de determinados grupos. Os documentos disponibilizados pela Secretaria de Educação constituem parte desse "aparato histórico" que silenciam outras vozes do passado e controlam a produção dessas memórias dificultando a construção de outras histórias. A partir dessa prática política o texto apresenta as quatro fases da divisão:

Primeira fase (1889-1930) - há formação das oligarquias sul-mato-grossense que lutam pelo reconhecimento da posse da terra. É nessas lutas que se manifesta a ideia divisionista. As oligarquias sulinas, nas lutas políticas, uniram-se às oligarquias de Cuiabá e através dessa aliança fizeram oposição armada ao governo estadual e à Matte Laranjeira. Percebe-se, nesse período, que era a elite formada pelos fazendeiros que defendia a ideia divisionista [...].

Segunda fase (1930-1945) - o movimento começa a organizar-se; as lutas armadas são substituídas por pressões políticas junto ao Governo Federal. Em 1932, os sul-mato-grossenses aliam-se aos paulistas e lutam na Revolução Constitucionalista. Nesse confronto armado os divisionistas e constitucionalistas são derrotados, e o novo Estado desaparece. Essa resolução serviu para 
divulgar a ideia divisionista, e Campo Grande torna-se o centro político de difusão do movimento.

Terceira Fase (1945-1964) - o novo Presidente da República é o General Eurico Gaspar Dutra, mato-grossense de Cuiabá, que adotou uma política de redemocratização. Em 1946 o governo federal extingue o Território de Ponta Porã, reintegrando a região ao Estado de Mato Grosso. Nesse período as iniciativas divisionistas são frustradas e a Companhia Matte Laranjeira mostra desinteresse em reflorestar os ervais.

Quarta Fase (1964-1977) - O golpe de 31 de março de 1964 põe fim a um período de democracia e inicia um regime militar autoritário. Os militares adotam a política do desenvolvimento com segurança. Nesse período, os políticos divisionistas aproximam-se dos militares e estudam (secretamente) as potencialidades políticas que impediam a divisão de Mato Grosso. Após vários estudos, o Presidente Ernesto Geisel assina em 11 de outubro de 1977 a Lei Complementar de no 31, que cria o Estado de Mato Grosso do Sul. (Movimento..., 2011)

Essa escrita historiográfica sobre a criação do Estado destaca os protagonistas dessa história, os grandes proprietários de terra, e suas intenções de separar a parte sul do Mato Grosso. Não há espaço para outros sujeitos e, a partir do ato de assinatura da lei, ocorre um movimento para afirmar uma memória política dos sujeitos que emergem nessa produção. Campo Grande, capital do estado, tem entre suas principais avenidas nomes de militares como Ernesto Geisel e Costa e Silva.

Podemos encontrar elementos dessa representação pública em textos produzidos por historiadores que voltaram suas atenções para a divisão do estado:

Assim, à guisa de conclusão reiteramos que o Estado de Mato Grosso do Sul "nasceu" depois de uma longa jornada separatista protagonizada pelos proprietários rurais no sul de Mato Grosso, onde se formou uma categoria de proprietários rurais, economicamente dominantes, que, com o tempo sobrepôs a do norte iniciando resistência a ele. (Vieira; Verde, 2010, p. 169)

As historiadoras Thaís L. Vieira e Aline X. Cana Verde têm como objeto de estudo o Movimento Guaicuru, mas ao tratar especificamente da divisão reiteram o protagonismo da elite sulista que se fortalece e consegue impor seu 
projeto de divisão sem que houvesse contestações internas em torno desse movimento. É importante trazer estas memórias reproduzidas na produção historiográfica para refletirmos sobre sua força de circulação em diferentes meios e para demonstrar como se tornam histórias ensinadas na educação básica.

O historiador Paulo Roberto Cimó Queiróz em artigo que analisa a divisão do estado e a produção de conflituosas identidades nas porções norte e sul do então Mato Grosso destaca a década de 1920 e a construção da ferrovia Noroeste do Brasil como um marco para o fortalecimento das elites sulistas:

Pelo que se pode perceber, foi ao longo da década de 1920 que começaram a manifestar-se, mais claramente, os efeitos considerados positivos da estrada de ferro Noroeste do Brasil, efeitos esses que se concentraram largamente na cidade de Campo Grande, sob a forma de rápido crescimento econômico e populacional. Foi nessa década, por exemplo, que essa cidade passou a concentrar as principais lideranças políticas do Sul, até então sediadas na cidade de Nioaque. (Queiróz, 2006, p. 158)

Nessa interpretação a cidade de Campo Grande, hoje capital de Mato Grosso do Sul, começa a concentrar maior força política com o advento da ferrovia. O crescimento econômico dessa região possibilitaria maior articulação das elites econômicas e, consequentemente, maior poder de articulação para criar meios de maior concentração de renda ao se fortalecerem politicamente.

A historiadora Marisa Bittar corrobora essa representação que coloca a chegada da ferrovia como um marco para as lutas separatistas. Além disso, destaca quem são os membros dessa elite

Olímpio Machado, Vespasiano Barbosa Martins, Eduardo Santos Pereira, Nicolau Fragelli, Laudelino Barcellos, Arlindo de Andrade, Arnaldo de Figueiredo, Demósthenes Martins, Laucídio Coelho e Fernando Corrêa da Costa. O rol apresentado revela, por um lado, uma elite política com formação intelectual aristocrática, oriunda das tradicionais e conceituadas Faculdades de Direito da época (Eduardo Olímpio Machado, Arlindo de Andrade) ou de Medicina (Vespasiano Barbosa Martins, Nicolau Fragelli, Fernando Corrêa da Costa), e, por outro, a classe social vinculada à posse de terras (Barbosa Martins, Coelho, Machado, Corrêa da Costa). O traço comum, entretanto, é a inserção na 
atividade política, que propiciou a alguns desses protagonistas alcançarem posição de relevo, como foi o caso de Vespasiano Barbosa Martins, Nicolau Fragelli, Arnaldo de Figueiredo e Fernando Corrêa da Costa, os dois últimos, ex-governadores de Mato Grosso. (Bittar, 1997, p. 145)

Aqui temos a divisão entre os membros dessa elite política, uma com formação intelectual e outra ligada às grandes propriedades, mas com o mesmo olhar político. Trata-se de um processo de divisão que tem esses sujeitos como principais protagonistas e um projeto de sociedade sem tensões produzidas por outros grupos. Esses trabalhos têm como questão central entender os movimentos políticos no âmbito do Estado para compreender as articulações nesse nível que justificaram a separação do território.

A produção historiográfica mais recente (Caetano, 2012; Amarilha, 2006) começou a questionar esse silenciamento de diferentes sujeitos durante o processo, ainda que não traga outras possibilidades em disputa sobre a divisão:

Isso significa que o que se conhece por Mato Grosso do Sul, embora seja fruto de uma decisão do general Geisel, não existiria não fosse o trabalho de artistas plásticos, poetas, músicos, escritores, folcloristas, memorialistas, historiadores circunscritos na produção regional. São esses indivíduos que trabalharam no sentido de construir saberes em torno da região. Assim, no momento da criação do Mato Grosso do Sul, cria-se a oportunidade de produzir discursos que legitimam a região, que lhe garantem um passado, mas que constitui um trabalho significativo de reelaboração de seus sentidos e significados, inclusive de invenção ficcional do próprio espaço. É de lá que se passa a produzir saberes em torno dessa região, claramente estruturados a partir de discursos essencialistas, a-históricos. (Caetano, 2012, p. 84)

Essa leitura do processo apresenta outros elementos significativos e retira dos generais e proprietários de terra o protagonismo alcançado por outras construções. Aqui, poetas e historiadores, entre outros homens das letras, são vistos como sujeitos importantes para que o estado existisse, pois cumprem o papel de legitimá-lo socialmente. Apesar de ressaltar a importância desses sujeitos, Caetano problematiza suas produções mostrando que não rompem totalmente com as representações produzidas nos palácios governamentais e atuam em sintonia, ajudando a construir uma memória que lhes agradasse: 
No caso de Mato Grosso do Sul, é explícito que alguns setores da sociedade, especialmente durante as duas primeiras décadas após a divisão do antigo Mato Grosso, ficaram mais próximos da administração estadual, ocupando importantes espaços de produção de saberes sobre a região. Não se pode ignorar, por exemplo, a atuação dos intelectuais vinculados à Academia Sul-Mato-Grossense de Letras (ASL) e ao Instituto Histórico e Geográfico de Mato Grosso do Sul (IHGMS), na proposta de formular uma memória coletiva e, consequentemente, a própria história da região [...] Ao mesmo tempo, não se pode ignorar a atuação dos artistas que surgem no contexto dos festivais de música popular em Campo Grande e que posteriormente vinculam-se à Fundação de Cultura de Mato Grosso do Sul (FCMS), transformando-se em agentes fundamentais na produção de identidades artísticas e culturais para a região. Além disso, destacam-se também os eventos organizados pela UFMS e pela TV Morena que, no curso dos anos 1980, não mediram esforços para promover e divulgar as produções artísticas consideradas regionais. (Caetano, 2012, p. 160)

Essa historiografia retira do silêncio artistas e intelectuais que emergem na cena história no período pós-separação aproveitando da ruptura institucional para conseguir criar espaços de poder. Para o ensino de História isso seria significativo por ampliar as possibilidades de interpretação do processo de separação do antigo estado de Mato Grosso e mostrar que a produção de memórias dominantes se faz no silenciamento de muitos.

Se o texto recomendado pela Secretaria de Educação que explica as disputas que levaram à criação do estado é monofônico, nas produções historiográficas vamos conseguindo ouvir outras vozes, ainda que estas não sejam totalmente dissonantes. Incorporar as novas interpretações vindas das produções historiográficas mais recentes ajuda a problematizar a história hegemônica e desconstruir o texto que hoje chega até as escolas que nomeiam e protagonizam um único grupo como os sujeitos desse movimento.

Essas novas leituras trazem para esta cena histórica grupos que ascendem nas brechas que a criação do novo estado permite. Entre eles está o movimento cultural Guaicuru, que entrou no debate para propor, assim como os intelectuais e artistas já citados, o que chamaram na época de nova identidade sul-mato-grossense. Esse movimento é importante nesta discussão sobre produção de memórias para entendermos como os grupos dominantes politicamente se apropriam de valores residuais para manter sua hegemonia. 
O movimento foi criando por um grupo de artistas e pesquisadores, entre eles "Henrique de Melo Spengler, Jonir Figueiredo, Luiz Antônio Torraca, Ilca Galvão, Adilson Schieffer, Luiz Xavier, Darwin Longo e outros” (Castro, 2017), e tinha como objetivo voltar-se "às questões da identidade cultural sul-mato-grossense a partir da implantação do estado em 1979, interesse esse que deu origem à Unidade Guaicuru de Cultura”. Para estabelecer essa nova "identidade" os integrantes do movimento produzem outra história do território, remontando-a ao século XVI e elevando os índios Guaicuru ao posto de protagonistas.

Segundo Humberto Espíndola,

e depois teve um equívoco muito grande, as pessoas acharam que o estado nasceu no dia em que o Geisel sapecou a caneta. Este é um grande equívoco de identidade... Trinta anos de Mato Grosso do Sul... Ninguém fala "500 anos da nação Guaicuru”. Porque, na verdade, as pessoas acham que o estado começou [há trinta anos]. Mas não, toda a história de Mato Grosso começa no Sul. A nação Guaicuru, que foi a última tribo indígena a se integrar no Império brasileiro, ela ficou até o último momento, até às vésperas do Império [cair] como nação Guaicuru, ninguém sabia se seria espanhola ou se seria portuguesa. Por um gesto de sabedoria do Império, quando fez dos caciques capitães do exército brasileiro, eles assumiram a posição de capitães do exército brasileiro e essa parte [aqui] ficou para o Brasil. Então, não há outra história indígena como a de Mato Grosso do Sul no país inteiro. Ninguém valoriza estes aspectos. O estado poderia ser estado Guaicuru, estado de Guaicuru. Porque nós teríamos a identidade de um povo que viveram aqui antes dos colonizadores chegarem. E conviveu com estes colonizadores. E que se tornou uma nação poderosa no século XVIII, perigosa, ao assimilar o cavalo do colonizador. (apud Neder, 2011, p. 222-223)

A discussão em torno da identidade possibilita a apresentação de outro enredo, outra história que faz emergir memórias divergentes que colocam em movimento outros sujeitos e outros protagonistas, neste caso, os indígenas da antiga "nação" Guaicuru. Na interpretação de Espíndola há um deslocamento importante ao instituir como marco da história do estado as ações dos índios ligados aos Guaicuru. Mesmo reforçando a capacidade de cooptação do Império brasileiro, essa história desconstrói a "linha evolutiva" que privilegiava a atuação dos homens brancos com poder político na região. 
A questão indígena no Mato Grosso do Sul sempre foi um tema muito sensível pela quantidade de povos que ainda residem no estado e pelos constantes massacres vividos por eles. Em 1996, portanto quase duas décadas após a separação, o jornal Diário da Serra, de Campo Grande, noticia as difíceis condições de vida nos índios Guarani-Kaiwá:

Ao deixar a tribuna chorando, depois de fazer um apelo dramático em defesa de todos os povos indígenas, o índio Anastácio Peralta provocou comoção entre muitas pessoas que assistiram ontem pela manhã a sessão solene que marcou a participação da Assembleia Legislativa nos eventos que celebram o Dia do Índio no Mato Grosso do Sul.

Representando a nação dos Guarani-Kaiwá, o mais numeroso grupo indígena do Estado, Peralta queixou-se de que ao longo das últimas décadas seus integrantes, entre os quais vem sendo registrado um número elevado de suicídios, "perderam a terra, a madeira e estão perdendo a língua", para em seguida advertir, no seu português precário:

"Homem branco é perigoso, meus companheiros" (Índio..., 1996, p. 8)

Essas relações ganham contornos mais dramáticos após a criação do novo estado e a política de expansão agrícola. Os grandes proprietários de terra atuam para manter o controle hegemônico da política estatal e aumentar seus ganhos. Para isso ocupam as terras indígenas e promovem seu lento e gradual extermínio:

Um conflito que já soma diversas mortes e persiste há décadas, a luta dos povos originários pela demarcação de terras no Mato Grosso do Sul (MS) se intensifica a cada dia. Ao passo que o estado é um dos que mais crescem economicamente, em decorrência do avanço do agronegócio, a violência e o número de assassinatos de índios é o maior do país, segundo dados do Conselho Indigenista Missionário (Cimi) [...]

Segundo a entidade, a produção agrícola em MS cresceu 1.493\% desde a safra 1977/78, passando de 987,2 mil toneladas para 15,7 milhões de toneladas previstas para a safra 2014/15. A área destinada ao plantio de grãos também aumentou consideravelmente - $191 \%$ no mesmo intervalo. 
Ao mesmo tempo, desde 2003, o Mato Grosso do Sul é o estado com maior número de assassinatos de índios. No ano passado, segundo o Cimi, 25 dos 70 casos aconteceram no estado. "O Mato Grosso do Sul é um estado majoritariamente ruralista e praticamente todas as fazendas estão em territórios tradicionais indígenas". (Freire, 2015)

Um estado cuja elite econômica se fortalece com a invasão de terras indígenas, sua expulsão para o interior e, em última instância, o seu massacre não conviveria bem com uma memória que coloca grupos indígenas como protagonistas da história. Nesse chão social as disputas não estavam limitadas a pensar qual a origem da identidade sul-mato-grossense, mas quem são os legítimos donos dessas terras. Portanto, reconhecer que a região é historicamente dominada pela ação indígena é, ao mesmo tempo, reconhecer que essas terras não podem ser expropriadas pelos novos membros da elite econômica.

A solução seria deslocar esse debate centrado na escolha política dos sujeitos para o tema da identidade, que retira a potência dos índios que viviam na região e disputavam o direito pela terra para o reconhecimento da importância histórica daqueles que não existiam mais, ressaltando determinadas características que faziam sentido para os grupos hegemônicos.

Em 1995 o artista plástico e historiador Henrique de Melo Spengler, um dos coordenadores do Movimento Guaicuru, escreve para o Movimento Tradicionalista Gaúcho de Mato Grosso do Sul esta correspondência:

O Estado de Mato Grosso do Sul foi criado em 11 de outubro de 1977, pela Lei Complementar no 31, sancionada pelo Gaúcho, então Presidente da República, Ernesto Geisel.

Não foi um ato arbitrário, foi o atendimento ao clamor de uma sociedade que mantivera acesa, por muitas gerações, a chama do ideal divisionista.

Nestas plagas, resistência e luta, autonomia e liberdade são valores de tradição que nos reportam diretamente à célebre Nação Guaicuru, de intrépidos guerreiros cavaleiros, que por muito tempo seguido manteve o domínio absoluto sobre este rincão.

Hoje o Guaicuru é símbolo do Homem sul-mato-grossense: é o elemento referencial da identidade e da cultura regional. (Spengler, 1995) 
No trecho da carta de Spengler para o representante de um movimento ligado aos proprietários de terra no estado percebemos como vão sendo incluídos os indígenas nessa história. Não é qualquer grupo indígena que poderia se tornar símbolo do homem sul-mato-grossense, eles deveriam ter determinadas características (guerreiros, resistentes) e ser sujeitos de um passado glorioso, mas não existiam mais, portanto eram sujeitos sem direitos. Estão excluídos, portanto, os diversos grupos que lutavam pela posse da terra. Nesse breve trecho percebe-se também uma junção de diferentes grupos que disputavam as terras no estado, dessa forma se tornam membros de uma "sociedade" que clamava pela divisão, um corpo unificado na busca pela "liberdade", "autonomia".

A discussão sobre a identidade sul-mato-grossense torna-se uma estratégia para a incorporação dos indígenas ao novo estado da Federação sem tensionar os grupos que detinham o poder econômico e sem discutir a luta pela terra. Nesse movimento a "nação Guaicuru" vai ganhando espaço com a imagem do povo guerreiro que não pertence mais à sociedade sul-mato-grossense. Primeiro são incorporados ao hino oficial do estado:

Os celeiros de fartura, sob um céu de puro azul,

Reforjaram em Mato Grosso do Sul

Uma gente audaz

Tuas matas e teus campos,

O esplendor do Pantanal

E teus rios são tão ricos

Que não há igual

A pujança e a grandeza,

De fertilidades mil

São o orgulho e a certeza

Do futuro do Brasil

Moldurados pelas serras,

Campos grandes: vacaria.

Rememoram desbravadores

Heróis, tanta galhardia

Vespasiano, Camisão 


\section{E o tenente Antonio João}

Guaicurus, Ricardo Franco

Glória e Tradição.

(Música de Radamés Gnattali.

Letra: Jorge Siufi e Otávio Gonçalves Gomes)

O hino foi instituído por decreto em 1979 e traz os índios Guaicuru junto a nomes de políticos como Vespasiano Barbosa Martins (prefeito de Campo Grande, 1934-1935; 1941-1942) considerado pela história oficializada no estado como um dos idealizados do novo território federal.

Ao longo da consolidação dos grupos políticos no poder outros processos de incorporação desses povos vão acontecendo:

Com a participação de 60 artistas, foi aberta na manhã de terça-feira, 19, a XV Mostra Guaicuru de Artes Visuais, tendo como palco o saguão do Palácio Guaicurus, sede da Assembleia Legislativa. O segundo-secretário da AL, deputado Sandro Fabi (PSB), falou em nome do Poder Legislativo, destacando a qualidade artística e histórica do Movimento Guaicuru [...] (Arte Guairucu..., 1999)

Dessa forma a questão indígena deixa de ser uma memória potencialmente questionadora sobre quem são os verdadeiros donos das terras no estado de Mato Grosso do Sul e é silenciada no ensino de História. Atualmente essa temática aparece no referencial curricular da rede estadual de ensino no $3^{\circ}$ ano do Ensino Fundamental, no conteúdo "Os movimentos na emancipação do sul do estado de Mato Grosso" (Secretaria..., 2012, p. 322). Alguns livros didáticos que interpretam esse processo histórico fazem referência aos Guaicuru e aos indígenas que vivem hoje no estado, mas sem referência à luta pela terra:

Os Guaicurus eram guerreiros e utilizavam os cavalos nos combates contra outros grupos indígenas e contra os colonizadores. Eles se deitavam na lateral dos cavalos para se protegerem contra [sic] o ataque dos inimigos. Quando os inimigos se aproximavam, eles se levantavam, utilizando suas lanças para enfrentá-los. [...]

Com a chegada dos europeus, muitos conflitos ocorreram entre eles e os indígenas que moravam nessa região, ocasionando muitas mortes e fuga de diversos grupos. 
Atualmente, vários grupos indígenas moram em aldeias, enquanto outros vivem nas cidades ou nas áreas rurais, como trabalhadores assalariados, muitas vezes, em difíceis condições de vida. (Dalfré, 2013, p. 25)

Compreendo que a produção didática tem referenciais teóricos e metodológicos específicos e uma já vasta gama de possibilidades de interpretação, tais como a indústria editorial e as teorias da recepção, como produtores de memórias, assim como os referenciais curriculares que são produzidos pelo estado, portanto um lugar social muito diferente do livro didático. É possível analisar cada uma dessas produções por supostos específicos, mas neste artigo nos interessa perceber como esses textos afirmam determinadas memórias e silenciam modos de vida alternativos.

O texto citado foi escrito para o $4^{\circ}$ ano, e nele é possível ver a descontinuidade da presença indígena no estado, que legitimaria sua luta pela posse da terra, pois a ausência dos atuais conflitos evidencia uma história que os retira da ação como sujeitos. Trago esses registros para mostrar que o fato de fazer referência aos indígenas como habitantes desse território, mostrar que vivem em condições difíceis, não significa que os potencializam como sujeitos, como protagonistas. Dessa forma, o texto impresso e distribuído pelo livro didático ajuda na consolidação de determinadas memórias dominantes porque não traz os valores que compõem a luta pela terra no estado do Mato Grosso do Sul.

Outros projetos emergiram para disputar o espaço político e simbólico com os homens ligados à pecuária e à agricultura. Em 1999 o então governador do Mato Grosso do Sul, José Orcírio Miranda dos Santos (o Zeca do PT), "lançou a ideia de mudar o nome de Mato Grosso do Sul para Pantanal" (Mato Grosso do Sul...,1999, p. 5). Era a tentativa de transformar as belezas naturais do Pantanal em polo turístico ou de construir uma indústria turística no estado que não se confirmou em função de diferentes fatores, entre eles a própria ação dos pecuaristas:

O MPF (Ministério Público Federal) realizou a operação "Água Limpa” para fiscalizar o fechamento de baías no rio Taquari, na região do Caronal, em Coxim. [...]

De acordo com Albrecht, essa prática acontece desde a década de [19]70 e a cada ano é renovada, fazendo com que o pescado fique escasso. "Não são os pescadores, muito menos os turistas que acabam com os peixes, mas sim o fechamento 
das baías, praticado a mando de latifundiários que usam poderio econômico sobre políticos para ficarem impunes", indigna-se o turismólogo. (Júnior, 2013)

Esse é o chão social em que diferentes sujeitos tentam disputar poder político e mesmo novas práticas econômicas. Tais conflitos são silenciados quando os processos históricos no estado são transformados em conhecimento a ser ensinado. Voltando ao texto didático, a autora faz um breve resumo sobre o Mato Grosso do Sul atual:

O Mato Grosso do Sul teve, nos últimos anos, o maior crescimento econômico da Região Centro-Oeste. O nosso estado tem sido considerado um rico celeiro agropecuário, sendo um dos principais produtores de soja, milho e algodão. E, também, um dos principais criadores de ave e gado bovino e suíno do país. Além disso, passou a investir na industrialização da sua produção agropecuária. (Dalfré, 2013, p. 19)

O recorte do texto é significativo para mostrarmos como se constituiu uma memória hegemônica sobre o estado, uma memória que tem como protagonistas os grandes proprietários de terra que no final da década de 1970 emergem em alguns trabalhos como responsáveis pela divisão do território e têm suas ações destacadas nos textos de apoio pedagógico sobre esse processo político. O livro didático emerge aqui como uma evidência da força dessa memória, pois sua produção envolve não só a concepção de história dos autores, mas a visão da indústria editorial e os valores daqueles que o recebem, os professores.

Os indígenas, suas ações e suas reivindicações são alijados dessas histórias ensinadas, relegados aos séculos XVI e XVII como os Guaicuru ou lembrados como aqueles que têm difíceis condições de vida na sociedade atual, mas nunca como homens e mulheres que lutam pelos seus direitos. Outras disputas sequer são mencionadas, e esse silenciamento não só reforça os poderes hegemônicos, também dificulta que professores de história problematizem tais memórias.

O processo aqui apresentado nos ajuda a entender um pouco da constituição política e econômica no estado de Mato Grosso do Sul e os conflitos vividos pelos grupos excluídos, notadamente os indígenas. Percebe-se a dificuldade não só de garantir seus direitos ao uso da terra como também de serem 
vistos como sujeitos dos processos históricos. Isso explica as visões preconceituosas e as dificuldades de serem reconhecidos como sujeitos de direito.

\section{REFERÊNCIAS}

AMARILHA, Carlos Magno Mieres. Os intelectuais e o poder: história, divisionismo e identidade em Mato Grosso do Sul. 2006. Dissertação (Mestrado em História) PPGH, Universidade Federal da Grande Dourados (UFGD). Dourados, 2006.

BITTAR, Marisa. Mato Grosso do Sul: do estado sonhado ao estado construído (18921997). 1997. Tese (Doutorado em História) - FFLCH, Universidade de São Paulo (USP). São Paulo, 1997.

CAETANO, Gilmar Lima. A música regional urbana e identidades culturais de Mato Grosso do Sul. 2012. Dissertação (Mestrado em História) - PPGH, Universidade Federal da Grande Dourados (UFGD). Dourados, 2012.

CASTRO, Marília de. “Henrique Splenger". Disponível em: http://www.oriondias.com. br/conteudos/henrique.pdf. Acesso em: 15 nov. 2017.

DALFRÉ, Liz Andréa. História e Geografia: Mato Grosso do Sul. 4º ano. Curitiba: Positivo, 2013.

HILL, Christopher. O mundo de ponta-cabeça: ideias radicais durante a Revolução Inglesa de 1640. São Paulo: Companhia das Letras, 1987.

NEDER, Álvaro Simões C. "Enquanto este novo trem atravessa o litoral central": Platinidad, poéticas do deslocamento e (des)construção identitária na canção popular urbana de Campo Grande/MS. 2011. Tese (Doutorado em Música) Universidade Federal do Estado do Rio de Janeiro (UniRio). Rio de Janeiro, 2011.

QUEIRÓZ, Paulo Roberto C. Mato Grosso/Mato Grosso do Sul: divisionismo e identidades (um breve ensaio). Diálogos, Maringá: DHI/PPH/UEM, v. 10, n. 2, p. 149184, 2006.

SILVA JÚNIOR, Renato Jales. Cidade e cultura: memórias e narrativas de viveres urbanos no bairro Bom Jesus Uberlândia-MG 1960-2000. 2006. Dissertação (Mestrado em Ciências Humanas) - Universidade Federal de Uberlândia (UFU). Uberlândia, 2006.

SILVA JÚNIOR, Renato Jales. Direito à memória: modos de viver e morar em Uberlândia entre as décadas de 1960 e 1980. 2013. Tese (Doutorado em Ciências Humanas) - Universidade Federal de Uberlândia UFU). Uberlândia, 2013.

THOMPSON, E. P. A formação da classe operária inglesa. v. I: A árvore da liberdade. Rio de Janeiro: Paz e Terra, 1987. 
VIEIRA, Thaís L.; VERDE, Aline X. Cana. Movimento divisionista e as diversas interpretações na historiografia: análise do Movimento Guaicuru. Albuquerque - revista de História, Campo Grande, v. 2, n. 3, p. 155-170, jan./jun. 2010.

WILLIAMS, Raymond. Base e superestrutura na teoria cultural marxista. Revista USP, São Paulo, n. 65, p. 210-224, mar./maio 2005.

\section{Fontes}

ARTE Guaicuru vai à Assembleia. Jornal O Repórter, Campo Grande, p. 5, 20 a 27 out. 1999.

FREIRE, Simone. Mato Grosso do Sul: agronegócio e violência. Brasil de Fato, 15 set. 2015.

ÍNDIO Guarani-Kaiwá critica o desrespeito dos brancos. Diário da Serra, Campo Grande, p. 8, 18 abr. 1996.

JUNIOR, Francisco. MPF faz operação para fiscalizar fechamento de baías do rio Taquari. Campo Grande News, Campo Grande, 2013.

MATO Grosso do Sul: qual o nome da nossa identidade? Correio do Estado, Campo Grande, 1999.

MOVIMENTO divisionista Sul-Mato-Grossense dividido em 4 fases. Disponível em: http://www.ilovemsoficial.com/2014/08/movimento-divisionista-sul-mato.html. Acesso em: 12 nov. 2017.

Artigo recebido em 27 de abril de 2018. Aprovado em 26 de junho de 2019. 